\title{
Direct and Indirect Factors Affecting Teachers' Burnout in the New Normal
}

\author{
Andrian A. Dela Cruz \\ Abra State Institute of Sciences and Technology Bangued Campus \\ https://orcid.org/0000-0002-9317-5488 \\ adelacruz@asist.edu.ph
}

\section{Abstract}

The outbreak of the COVID-19 has brought about tiring tasks and unending demands in the Philippine educational system. With the abrupt shift of the teaching-learning process, teachers are pressured and stressed, which leads them to be burned out. The descriptive correlational research design determines the direct and indirect effects of perceived control to burnout through teachers' personality traits of the 240 early childhood teachers. Data are analyzed using the Pearson r formula, Bivariate parametric correlation, and the Structural Equation Model (SEM). The study reveals that despite the challenges experienced in this time of pandemic, teachers have control over themselves and with the people around them. The teachers' level of control does not influence their burnout; instead, their burnout is dependent on their emotional stability. Thus, burnout is a personal choice which is triggered by one's emotion. A person with high perceived control may still be burned out if he does not have control over his emotions.

Keywords: education, perceived control, teachers' personality traits, teachers' burnout, descriptive correlational, Philippines

\subsection{Introduction}

The outbreak of the coronavirus brought about tiring changes and unending demands to all walks of life worldwide. With the changing face in the Philippine educational system, teachers are among the affected sectors which need to adjust in meeting the standards of the new normal setup due to this pandemic. The online and modular modalities to name a few, are among the top most concerns of teachers which require reproduction, distribution, and even the retrieval of the learning packages. Aside from these, teachers find it challenging too in preparing and delivering technology-based instruction like the Learning Management System (LMS), an application for teachers in uploading their learning packages and digital lessons for the online classes. With the accountabilities in the new normal, teachers are frightened, pressured, and stressed which can result to burnout.

As defined by the World Health Organization (2019), burnout is a syndrome resulting in 
workplace stress which is unsuccessfully managed. It has three dimensions, feelings of energy depletion and exhaustion, cynicism related to one's job, and reduced professional efficacy. Among occupations, teaching is considered as one among the highly stressful jobs (Johnson, et al. 2005) yielding to burnout due to their work demands (Pillay, H. et al., 2005).

Researchers constructed possible reasons for teachers' burnout pointing to teachers' perceived control. As defined by Chipperfield, et al. (2012) perceived control involves influence over one's action and contingency beliefs that a given response will influence an outcome. According to Pei, et al. (2009), the higher the perceived control, the lower the three dimensions of job burnout. Moreover, perceived control affects psychological health through emotional exhaustion. The higher the perceived control, the lower emotional exhaustion, and the better psychological health will become. Hence, classroom teachers who cannot control situations in their lives are more likely to suffer from burnout that makes them less effective and leave the profession. (Bevis, 2008;
Fore, et al., 2002)

Teaching as a profession is looked at by other occupations at the highest pedestal bringing honor and glory to teachers. However, this reputation is questioned with arguments which contribute to the burnout issues of teachers which affect their professional commitment leading to low learning and output in the educational settings (Colomeischi, A. \& Colomeischi, T., 2014). Overcoming these issues is one way to prepare teachers holistically ensuring effective and efficient delivery of instruction in the new normal.

To obtain a more stress-free lifestyle in the new normal among early childhood teachers, this paper studies the relationship between perceived control and teachers' burnout through teachers' personality.

\section{Conceptual Framework}

The model shows the perceived control, extraversion, agreeableness, conscientiousness, emotional stability, and intellect/imagination personality traits as variables that influence teachers' burnout.

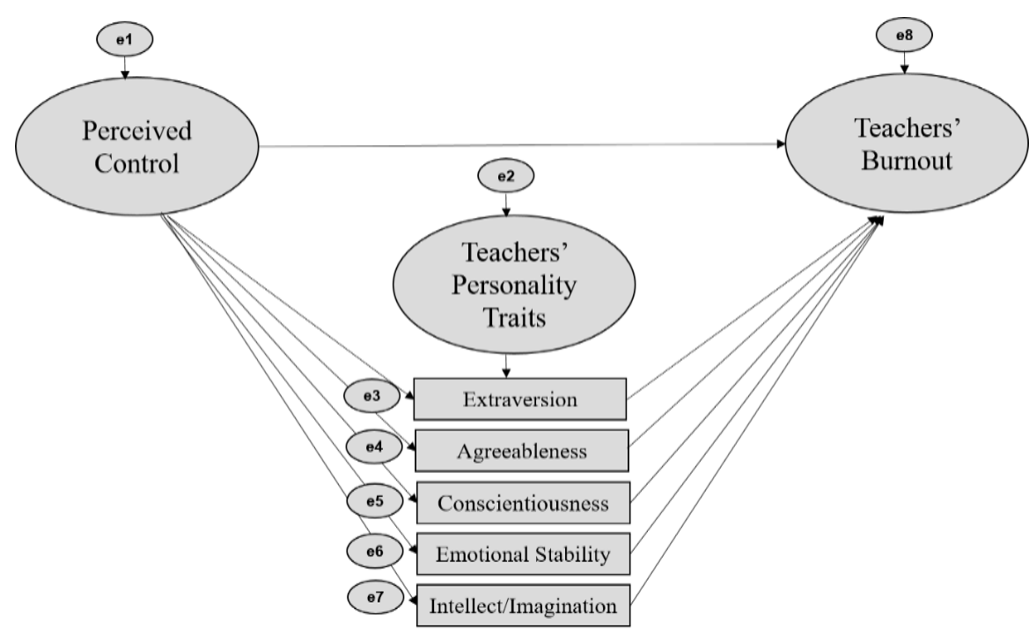

Figure 1. The Research Paradigm 
The study suggests that perceived control can be a possible future variable that directly relates to teachers' burnout. The present study explores the relationship between perceived control as a variable of teachers' personality in dealing with teachers' burnout.

\section{Objectives}

The study determines the direct and indirect effects of perceived control of teachers' burnout through teachers' personality traits. On the other hand, it determines the perceived control, the teachers' personality traits, and the level of teachers' burnout as perceived by the respondents. Likewise, the relationship between or among the perceived control, teachers' personality traits, and teachers' burnout is determined too.

\subsection{Methodology}

This study used the quantitative method utilizing the descriptive correlational research design. This utilized the descriptive approach as it described the level of teachers' burnout, teachers' personality traits, and the perceived control of the respondents. On the other hand, this further used correlational design because it examined the relationships between or among the variables.

The respondents of the study came from the three (3) biggest districts in the Schools Division of Abra, namely: Bangued District, Tayum-Dolores District, and Manabo-Bucay District. The researcher used a multi-stage and random sampling technique to identify the respondents of the study from the districts above. Also, a Gpower 3.1.9.4 an online sample size calculator was used to obtain a sample size of 240 early childhood teachers (Kindergarten and Grades 1 to 3 teachers) with a $95 \%$ confidence interval of 5.52, a percentage of 50 , and a population of 1005 .
The following survey instruments measured the variables of the study: The interactive version of the Spheres of Control Scale (SOC-3) was developed by Paulhus (1990) designed to assess the personal control, interpersonal control and socio-political control. It is a multidimensional 30item scale with 7- point Likert scales ranging from "very strongly disagree" to "very strongly agree". The scale's Cronbach's alpha is .80, which means the interactive version of the Spheres of Control Scale (SOC-3) is highly reliable.

The second instrument is the The BigFive Personality Traits Test. It is considered as the best accepted and most commonly used model of personality in academic psychology which was developed by Goldberg (1992). It is a 50-item personality test that measures the five dimensions of personality traits: extraversion, agreeableness, conscientiousness, emotional stability, and intellect/imagination. Extraversion is one of the dimensions of a teachers' personality which explains how well a person loves to be with other people, enjoys get-togethers, and is full of energy. Agreeableness is another personality trait that must be present among teachers. It connotes individuals who are warm, friendly, and tactful. Conscientiousness, just like the other aforementioned traits are important personality traits among teachers. It refers to how responsible, organized, hard-working, and goal-directed persons are. Emotional Stability is a personality trait maintaining good composure under emotional stress. Lastly, intellect/imagination is a teachers' trait that deals with creativity and curiosity.

It has 5-point Likert scales ranging from "very inaccurate" to "very accurate". Analysis of its reliability using the actual data of the study yielded a Cronbach's alpha of .892, which means that it is highly reliable. The last instrument is the 
Teachers' Burnout Scale which was developed by Richmond, et al., (2001). It is a 20-item scale which measures the emotional exhaustions, cynicism, and the feelings of reduced professional ability among teachers. Burnout can lead to very aberrant behavior on teachers which includes resignation, emotional outbursts, and other irrational behaviors. It has 5-point Likert scale ranging from "strongly disagree" to "strongly agree". Analysis of its reliability using the actual data of the study yielded a Cronbach's alpha of .953, which means that it is highly reliable.

The researcher imported the excel data in the SPSS software to check the normality of data using the Shapiro Wilk test. Table 1 shows that the data were standard. Several statistical formulae answered the statement of the problems of this study. Statement problem numbers one to three were analyzed using mean and standard deviation to describe perceived control, teachers' personality traits, and teachers' burnout of the respondents. Relationships between or among variables were analyzed using the Pearson $r$ formula. The Bivariate parametric correlation and other descriptive analyses were done in the SPSS IBM version 20 software. Moreover, Structural Equation Model (SEM) was also used to analyze the direct and indirect effect of perceived control on teachers' burnout through teachers' personality traits.

The Shapiro-Wilk test shows the distribution of data with a significance value of more than .05. It examines whether variables are generally distributed in the given population, an alternative for the Kolmogorov-Smirnov test.

Table 1. Test of Normality

\begin{tabular}{lccc}
\hline \multirow{2}{*}{ Variables } & \multicolumn{3}{c}{ Shapiro-Wilk } \\
\cline { 2 - 4 } & Statistic & Df & Significance \\
\hline Personal Control & .993 & 236 & .330 \\
Interpersonal Control & .990 & 236 & .106 \\
Socio-political Control & .983 & 236 & .077 \\
Extroversion & .990 & 236 & .105 \\
Agreeableness & .992 & 236 & .255 \\
Conscientiousness & .993 & 236 & .282 \\
Intellect/Imagination & .989 & 236 & .069 \\
Emotional Stability & .992 & 236 & .250 \\
Teacher Burnout & .939 & 236 & .057 \\
\hline
\end{tabular}

\subsection{Results and Discussion}

Table 2 discloses the perceived control of the respondents along personal, interpersonal, and socio-political. On the whole, the respondents agreed to have a level of perceived control
$(M=4.723, S D=.723)$. The data revealed that the respondents have the highest perception of control along personal $(M=4.943, S D=.756)$ followed by socio-political $(M=4.704, S D=.806)$, and the interpersonal $(M=4.522, S D=.800)$. It means 
that the respondents' teaching career is somehow beyond their control as a result of their hard works, determination, and good relationship with their peers. It implies that the respondents recognize their responsibility, develop a relationship with peers, and take an active part in the political and social affairs, which they perceived as factors highlighting their teaching career. According to Toussi and Ghanizadeh (2012) the extent to which people control the events that impact their lives are linked with the perception of having more control over life circumstances and more personal responsibility for outcomes.

The early childhood teachers in the Schools Division of Abra, like any other teacher nationwide, have varied perceptions of control. They agreed to some extent that personal, interpersonal, and socio-political factors can affect themselves. As the finding suggests, they believed that they have control over their lives, the peers they work with and the society they belong to. Amidst the new setup in the education system, they can still manage to control the situation and provide the best and appropriate learning modality for their learners.

Table 2. Perceived Control of the Respondents in terms of Personal Control, Interpersonal Control, Socio-Political Control

\begin{tabular}{|c|c|c|c|c|}
\hline \multicolumn{3}{|c|}{ Variables } & Mean & $\begin{array}{l}\text { Standard } \\
\text { Deviation }\end{array}$ \\
\hline \multicolumn{3}{|c|}{ Perceived Control } & 4.723 & .723 \\
\hline \multicolumn{3}{|c|}{ Personal Control } & 4.943 & .756 \\
\hline \multicolumn{3}{|c|}{ Interpersonal Control } & 4.522 & .800 \\
\hline \multicolumn{3}{|c|}{ Socio-political Control } & 4.704 & .806 \\
\hline \multicolumn{5}{|l|}{ Range Means } \\
\hline $\begin{array}{c}\text { Point Values } \\
7\end{array}$ & $\begin{array}{l}\text { Statistical Limit } \\
\quad 6.15-7.00\end{array}$ & \multicolumn{3}{|c|}{$\begin{array}{l}\text { Descriptive Interpretation } \\
\text { Very Strongly Agree }\end{array}$} \\
\hline 6 & 5.29-6.14 & \multicolumn{3}{|c|}{ Strongly Agree } \\
\hline 5 & $4.43-5.28$ & \multicolumn{3}{|c|}{ Agree } \\
\hline 4 & $3.57-4.42$ & \multicolumn{3}{|c|}{ Neither Agree Nor Disagree } \\
\hline 3 & $2.71-3.56$ & \multicolumn{3}{|c|}{ Disagree } \\
\hline 2 & $1.85-2.70$ & \multicolumn{3}{|c|}{ Strongly Disagree } \\
\hline 1 & $1.00-1.84$ & \multicolumn{3}{|c|}{ Very Strongly Disagree } \\
\hline
\end{tabular}

Table 3. Teacher's Personality Traits in terms of Agreeableness, Extraversion, Conscientiousness, Emotional Stability, and Intellect/Imagination

\begin{tabular}{|c|c|c|c|}
\hline \multicolumn{2}{|c|}{ Variables } & Mean & $\begin{array}{l}\text { Standard } \\
\text { Deviation }\end{array}$ \\
\hline \multicolumn{2}{|c|}{ Extraversion } & 3.167 & .380 \\
\hline \multicolumn{2}{|c|}{ Agreeableness } & 3.286 & .413 \\
\hline \multicolumn{2}{|c|}{ Conscientiousness } & 3.315 & .397 \\
\hline \multicolumn{2}{|c|}{ Emotional Stability } & 2.974 & .540 \\
\hline \multicolumn{2}{|c|}{ Intellect/Imagination } & 3.201 & .399 \\
\hline \multicolumn{4}{|l|}{ Range Means } \\
\hline \multicolumn{2}{|c|}{$\begin{array}{cc}\text { Point Values } & \text { Statistical Limit } \\
5 & 4.20-5.00\end{array}$} & \multicolumn{2}{|c|}{$\begin{array}{l}\text { Descriptive Interpretation } \\
\text { Very Accurate }\end{array}$} \\
\hline 4 & $3.40-4.19$ & \multicolumn{2}{|c|}{ Moderately Accurate } \\
\hline 3 & $2.60-3.39$ & \multicolumn{2}{|c|}{ Neither Accurate Nor Inaccurate } \\
\hline 2 & $1.80-2.59$ & \multicolumn{2}{|c|}{ Moderately Inaccurate } \\
\hline 1 & $1.00-1.79$ & \multicolumn{2}{|l|}{ Very Inaccurate } \\
\hline
\end{tabular}

Table 3 reveals the personality of the early childhood teachers. The respondents described their personality traits along extraversion $(M=$ 3.167, $S D=.380)$, agreeableness $(M=3.286$, $\mathrm{SD}=.413)$, conscientiousness $(\mathrm{M}=3.315, \mathrm{SD}=.397)$, and intellect/imagination ( $M=3.201, S D=.399)$ as neither accurate nor inaccurate. The data along extraversion suggest that some of the respondents are friendly and action-oriented while others are reserved and preferred to work at their own pace. Göncz (2017) found that reasonable extraversion is necessary with friendliness, self-confidence, and positive emotions. Kim, Verna, et al. (2019) affirmed that classroom teaching requires confidence for social interaction. Thus, gregariousness, persuasiveness, and sociability, which are associated with extraversion, are advantageous traits in the teaching-learning process.

In terms of agreeableness, the data revealed that some of the respondents are somehow compassionate, eager to please, and prefer cooperation over competition. Various studies explain the importance of having high level of 
agreeableness to both teachers and students: teachers become more emphatic, altruistic, and friendly it creates positive and conducive learning environments needed by the students, and the most substantial for teachers' evaluation (Tamban \& Banasihan, 2017; Pianta \& Hamre, 2009; Kim \& MacCann, 2018).

On the other hand, the data regarding conscientiousness revealed that the respondents are systematic and have strong sense of responsibility but are sometimes less focused. Related studies as to John et al. (2008), affirmed that a high level of conscientiousness helps individuals to be highly focused, responsible and organized, organization and planning make teachers effective, and conscientiousness is associated with teacher effectiveness measures (Klassen et al., 2017; Garcia et al., 2011).

Moreover, the data with regard to intellectual/ imagination confirms that some of the respondents are receptive to trying new experiences and ideas. They often look at themselves as imaginative, creative, and willing to consider the opinions and views of others. The advantages of having high intellect/imagination trait are confirmed by scholars (John et al., 2008) improves intellectual curiosity (Judge et al., 2013) good predictor of job performance, (Klassen et al., 2017) helps teachers be more flexible, and (Patrick, 2011) predicts students' academic competencies.

However, only along with emotional stability where the respondents described their personality as moderately inaccurate. It means that the respondents are less emotionally stable and have a hard time managing their emotional competencies. Hence, they are more likely to be prone to negative emotions and anxiety. According to an article posted by Corcoran (2017) that the mastery of emotional competencies of teachers is a lifelong and enduring process considering the tedious works, accountability to students and families at home.

The bulk of paperwork, aside from the required number of modules needed to be prepared, reproduced, distributed, and retrieved, is the timeless sacrifice that teachers must overcome in the new normal. The limited access to both processes and means of utilizing technological platforms and contextualizing the learning delivery modality poses many challenges to teachers in the new normal setting.

The recent survey from the Yale Center for Emotional Intelligence and the Collaborative for Social-Emotional and Academic Learning has revealed that lots of educators in the United States are anxious, fearful, worried, and sad during this pandemic. These stress-related feelings are due to their fear that COVID-19 can affect not only them but their families too, aside from the burden that awaits them in handling classes in the new normal set-up (Cipriano \& Brackett, 2020). Hence, this makes the teaching profession as one of the most stressful and fearful careers of today, affecting both the personality and performance of teachers.

As disclosed in the different studies by Frenzel et al. (2009), Kim, Verena, et al. (2019) and Becker, et al. (2014), teachers' emotions are transmittable to students and can influence class emotion and the quality of the lesson as well. As Khatoon (2015) pointed that high level of emotional stability helps teachers experience more remarkable professionalism. Sheema (2005) found out that only emotionally stable people can experience genuine empathy. 
Table 4. Teachers' Burnout

\begin{tabular}{|c|c|c|c|}
\hline \multicolumn{2}{|c|}{ Variable } & Mean & $\begin{array}{l}\text { Standard } \\
\text { Deviation }\end{array}$ \\
\hline \multicolumn{2}{|c|}{ Teachers' Burnout } & 1.564 & .495 \\
\hline \multicolumn{4}{|l|}{ Range Means } \\
\hline $\begin{array}{l}\text { Point Values } \\
\quad 5\end{array}$ & $\begin{array}{l}\text { Statistical Limit } \\
\quad 4.20-5.00\end{array}$ & \multicolumn{2}{|c|}{$\begin{array}{l}\text { Descriptive Interpretation } \\
\text { Extremely Severe Burnout Feelings }\end{array}$} \\
\hline 4 & $3.40-4.19$ & \multicolumn{2}{|c|}{ Severe Burnout Feelings } \\
\hline 3 & $2.60-3.39$ & \multicolumn{2}{|c|}{ Substantial Burnout Feelings } \\
\hline 2 & $1.80-2.59$ & \multicolumn{2}{|c|}{ Strong Burnout Feelings } \\
\hline 1 & $1.00-1.79$ & \multicolumn{2}{|c|}{ Few Burnout Feelings } \\
\hline
\end{tabular}

Table 4 explains that the respondents have few burnout feelings with $(M=1.564, S D=.495)$. It means that their level of burnout is not that too serious and is still manageable and tolerable to some extent. It implies that the respondents look positively at the different challenges they encounter with their teaching job and responsibilities, communicating with students, and socializing with colleagues.

Classroom teaching can be very stressful (Kyriacou 2001). Common factors that can lead to stress are the number of teaching preparations, high demands for work quality, and teaching personality, which are possible to encounter during this pandemic times. These stressful teaching experiences can lead to burnout (Evers et al., 2014). However, Colomeischi, A. and Colomeischi, T. (2014) concluded that teachers' personalities could influence teaching satisfaction regardless of school-related challenges. Further, they found out that burnout can be possible only for unsatisfied teachers.

Even though early childhood teachers in the Schools Division of Abra are often exposed to stressful situations and loaded with teaching preparations, they still manage to combat these with their resilient personality. This personality of Filipino teachers is well-known and lauded globally. In an article posted by Tanjutco (2017) in usa. inquirer.net, reputable employers abroad praised Filipino teachers because they exhibit excellence, high level of professionalism, and the highest sense of responsibility. Reyes and Valencia (2014) confirmed in their study the competitive edge of migrant Filipino teachers abroad. Viernes and de Guzman (2005) stated that Filipino teachers accept that tension and conflict are parts of their teaching career; hence, they are not seriously bothered and affected by them.

Table 5. Relationships of Perceived Control, Teachers' Personality, and Teachers' Burnout

\begin{tabular}{|l|c|c|c|c|c|c|c|c|c|}
\hline \multicolumn{1}{|c|}{ Variables } & 1 & 2 & 3 & 4 & 5 & 6 & 7 & 8 & 9 \\
\hline $\begin{array}{l}\text { 1.Personal Control } \\
\text { 2.Interpersonal } \\
\text { Control }\end{array}$ & $-.775^{* *}$ & - & & & & & & & \\
\hline $\begin{array}{l}\text { 3.Socio-political } \\
\text { Control }\end{array}$ & $.756^{* *}$ & $.769^{* *}$ & - & & & & & & \\
\hline 4.Agreeableness & $.188^{* *}$ & $.168^{* *}$ & $.141^{*}$ & - & & & & & \\
\hline 5.Extraversion & $.190^{* *}$ & .101 & .109 & $.640^{* *}$ & - & & & & \\
\hline 6.Conscientiousness & $.235^{* *}$ & $.186^{* *}$ & $.192^{* *}$ & $.628^{* *}$ & $.672^{* *}$ & - & & & \\
\hline 7.Emotional Stability & $.295^{* *}$ & $.242^{* *}$ & $.202^{* *}$ & $.455^{* *}$ & $.520^{* *}$ & $.465^{* *}$ & - & & \\
\hline 8.Intellect/Imagination & $.160^{*}$ & .074 & .032 & $.661^{* *}$ & $.649^{* *}$ & $.655^{* *}$ & $.527^{* *}$ & - & \\
\hline 9.Teachers' Burnout & -.063 & -.036 & -.064 & -.004 & .014 & -.086 & $-.176^{* *}$ & -.006 & - \\
\hline
\end{tabular}


Table 5 reveals the relationship of perceived control, the five teachers' personality traits and the teachers' burnout. It was found out that the three dimensions of perceived control are positively associated with extraversion, conscientiousness, and emotional stability teachers' personality traits while only agreeableness and intellectual/ imagination traits are positively correlated with personal control. However, although the resulting p-values are significant, all r-values between perceived control and the five teachers' personality traits are below 0.29, which is interpreted as low correlation. This explains that the level of perceived control does not really contribute and affect the five teachers' personality traits which are considered in this study as variables of teachers' burnout.

However, this finding negates some important constructs which argued positive relationships of perceived control to teachers' personality. Pagnini, et al. (2016) suggests that life satisfaction is possible when people can exert control. Likewise, Thompson and Spacapan (2010) affirmed that individuals with greater perceptions of control are not prone to depression. More so, Dilekmen and Erdem (2013) stated that depression is a severe psychological problem that could lead to low teachers' personality. Educational research, as cited by Hammarberg, A. (2003), stated that teachers with high perceived control are more flexible in the teaching-learning process than those with low perceived control. Thus, according to Tsytsarev and Shiryaev (2017), teachers who have control over the situations are more likely to experience life satisfaction and happiness in teaching.

On the other hand, the table confirms the negative relationship between teachers' burnout to the emotional stability of teachers $(r=-.176$, $p<.01$ ). It means that as the emotional stability of teachers increases, burnout decreases. It implies that emotional stability is a contributory factor of burnout among teachers.

The result confirms with the studies arguing that teaching can be stressful (Kyriacou, 2001), which may lead to burnout (Colomeischi, A. \& Colomeischi, T., 2014), and emotional exhaustion (Maslach et al., 2001). Teachers' personality is found to be one of the identified factors of burnout (Chang, 2009), and to overcome burnout, teachers should establish strong emotional foundation (Yazon \& Manaig, 2019).

Table 6 indicates the path analysis of the variables. The path from perceived control shows a direct effect to teachers' personality along with extraversion $(\beta=.096, p<.05)$; agreeableness $(\beta=.083, \quad p<.05) ; \quad$ conscientiousness $(\beta=.122$, $p<.01)$; and emotional stability $(\beta=.199, p<.01)$. Moreover, the path shows a direct effect of emotional stability to burnout $(\beta=.276, p<.01)$. However, although the $p$-levels are gleaned to be significant, the beta weight of the aforementioned values are too small or low, which only implies that the strength of relationship between the perceived control and the five personality traits is weak.

It only means that teachers' personality traits do not directly affect the burnout issues among teachers. Likewise, the increase or decrease on the emotional stability personality traits of teachers with the presence of the perceived control could not be directly responsible for them to experience burnout issues in the new normal education. Their level of perceived control does not influence burnout among them but could be dependent on their emotional stability. Thus, burnout issues could be an innate choice or a personal choice which could be triggered by one's emotion. A person with high perceived control may still be burned out if he does not have control over his emotions. 
Table 6. Direct and Indirect Effect of Perceived Control on Teachers' Burnout through Teachers' Personality

\begin{tabular}{lllccc}
\hline & Path & & $\begin{array}{c}\text { Beta } \\
\text { Weights }\end{array}$ & $\begin{array}{c}\text { Standard } \\
\text { Error }\end{array}$ & $\begin{array}{c}\text { Significance } \\
\text { (p-level) }\end{array}$ \\
\hline Extraversion & $<---$ & Perceived Control & .096 & .034 & .004 \\
Agreeableness & $<---$ & Perceived Control & .083 & .037 & .023 \\
Conscientiousness & $<--$ & Perceived Control & .122 & .035 & .000 \\
Emotional Stability & $<---$ & Perceived Control & .199 & .047 & .000 \\
Intellect Imagination & $<---$ & Perceived Control & .052 & .036 & .141 \\
Teacher Burnout & $<---$ & Perceived Control & -.082 & .048 & .088 \\
Teacher Burnout & $<---$ & Extraversion & .014 & .082 & .862 \\
Teacher Burnout & $<---$ & Agreeableness & .024 & .075 & .751 \\
Teacher Burnout & $<---$ & Conscientiousness & -.089 & .080 & .321 \\
Teacher Burnout & $<--$ & Emotional Stability & .276 & .059 & .000 \\
Teacher Burnout & $<--$ & Intellect/Imagination & -.080 & .077 & .302 \\
\hline
\end{tabular}

\subsection{Conclusions}

The study yields a timely result which can be used as an insight for school officials or heads. Teachers, despite the bulk of their work and challenges in this time of pandemic, still have control over themselves, their plans and their work. They have control over their relationship with other people and still can socialize with them. Moreover, they are in control of the events that surround them, not minding the problems of others but more focused on what to do within their own capability. Their level of control does not influence their burnout; instead, their burnout is dependent on their emotional stability. Thus, burnout is an innate choice or a personal choice which is triggered by one's emotion. A person with high perceived control may still be burned out if he does not have control over his emotions.
Therefore, more workload and tasks among teachers may not be a cause for burnout. However, when they are reprimanded for a little mistake, or scolded for a late report, their saddened emotions will trigger the burnout.

\section{Recommendations}

In the light of the findings and conclusions, the researcher recommends the continuous development of an excellent personal relationship with peers to uplift the relatively low perceived control. Moreover, the sustainable implementation of the Professional Development Plan is deemed necessary to address the low emotional stability, which can contribute to the burnout issue among early childhood teachers in the new normal education. 


\section{References}

Becker, E., Götz, T., Morger, V., \& Ranellucci, J. (2014). The importance of teachers' emotions and instructional behavior for their students' emotions: An experience sampling analysis. Teaching and Teacher Education, 43, 15-26. https://doi.org/10.1016/j.tate.2014.05.002

Bevis, K. (2008). Teacher Burnout: Locus of Control and its Correlation to Teacher Burnout and Job Satisfaction. Theses, Dissertations and Capstones, 466. https://mds.marshall.edu/ etd/466

Chang, M.-L. (2009). An appraisal perspective of teacher burnout: Examining the emotional work of teachers. Educational Psychology Review, 21(3), 193-218. https://doi. org/10.1007/s10648-009-9106-y

Chipperfield, J. G., Perry, R. P., \& Stewart, T. L. (2012). Perceived control. https://www. researchgate.net/publication/316747941_ Perceived_control

Cipriano, C. \& Brackett, M. (2020). Teachers are anxious and overwhelmed. They need SEL now more than ever. https://www.edsurge. com/

Colomeischi, A. \& Colomeischi, T. (2014). Teachers' attitudes towards work in relation with emotional intelligence and self-efficacy. Procedia-Social and Behavioral Sciences, 159, 615-619.

Corcoran, R. (2017). Teachers' emotions. https:// irinstitutes.org/teacher- emotions/
Dilekmen, M \& Erdem, B. (2013). Depression levels of elementary school teachers. Procedia Social and Behavioral Sciences, 106 (2013), $793-806$.

Evers, W., Tomic, W., Brouwers, A. (2004). Burnout among teachers students' and teachers' perceptions compared. School Psychology International, 25(2), 131-148.

Frenzel, A.C., Lu“dtke, O., Pekrun, R., Goetz, T., \& Sutton, R. (2009). Emotion transmission in the classroom: Exploring the relationships between teacher, and student enjoyment. Journal of Educational Psychology, 101(3), 705-716.

Fore, C., Martin, C., \& Bender, W. (2002). Teacher burnout in special education: The causes and the recommended solutions. The High School Journal, 86(1), 36-44. https://www. jstor.org/stable/40364344.

Garcia, P. L. S., Kupczynski, L., \& Holland, G. (2011). The impact of teacher personality styles on the academic excellence of secondary students. National Forum of Teacher Education Journal, 21, 1-8.

Goldberg, Lewis R. (1992). The development of markers for the Big-Five factor structure. Psychological assessment, 4(1), 26.

Göncz, L. (2017). Teacher personality: a review of psychological research and guidelines for a more comprehensive theory in educational psychology, Open Review of Educational Research, 4(1), 75-95. https://doi.org/10.108 0/23265507.2017.1339572 
Hammarberg, A. (2003). Pre-school teachers' perceived control and problem behaviours in children. Acta Universitatis Upsaliensis, 123(56).

John, O. P., Naumann, L. P., \& Soto, C. J. (2008). The Paradigm shift to the integrative big five trait taxonomy. Handbook of Personality: Theory and Research, 3, 114-158.

Johnson, S., Cooper, C., Cartwright, S., Donald, I., Taylor, P., \& Millet, C. (2005). The experience of work-related stress across occupations. Journal of Managerial Psychology, 20, 178-187. https://doi. org/10.1108/02683940510579803

Judge, T. A., Rodell, J. B., Klinger, R. L., Simon, L. S., \& Crawford, E. R. (2013). Hierarchical representations of the five-factor model of personality in predicting job performance: Integrating three organizing frameworks with two theoretical perspectives. Journal of Applied Psychology, 98, 875-925.

Khatoon, N. (2015). Emotional stability, Self Professional Development and Its Role in Effective Teaching. International Journal of Business and General Management, 4(4), 9-14.

Klassen, R. M., Durksen, T., Kim, L., Patterson, F. Rowett, E., Warwick, J., Warwick, P., Wolpert, M. et al. (2017). Developing a proof-ofconcept selection test for entry into primary teacher education programs. International Journal of Assessment Tools in Education, 4, 96-114.

Kim, L. E., \& MacCann, C. (2018). Instructor personality matters for student evaluations: Evidence from two subject areas at university. British Journal of Educational Psychology, 88, 584-605, 4.

Kim, L. E, Verena Jörg \& Robert M. Klassen (2019) A meta-analysis of the effects of teacher personality on teacher effectiveness and burnout. Educational Psychology Review, 31, 163-195.

Kyriacou, C. (2001). Teacher stress: Directions for future research. Educational Review, 53, 2735.

Maslach, C., Schaufeli, W. B., \& Leiter, M. P. (2001). Job burnout. Annual Review of Psychology, $52,397-422$

Patrick, C. L. (2011). Student evaluations of teaching: Effects of the big five personality traits, grades, and the validity hypothesis. Assessment \& Evaluation in Higher Education, 36, 239-249.

Paulhus, D. (1990). The sphere of control scale: 10 yrs of research. Personality and Individual Differences, 32(1), 121-131. https://doi. org/10.1016/S0191-8869(01)00010-1

Pagnini, F., Bercovitz, K., \& Langer, E. (2016). Perceived control and mindfulness: Implications for clinical practice. Journal of Psychotherapy Integration, 26(2), 91-102. https://doi.org/10.1037/int0000035

Pei, G.-g., Li, W.-d., \& Zhang, J.-x. (2009). Perceived control, perceived organizational support, job burnout, and psychological health of 
officers in Chinese armed police force: An Structural Equation Modeling study. Chinese Journal of Clinical Psychology, 17(1), 115-117. praised and in demand in the US. https:// usa.inquirer.net/8169/filipino-teachershighly-praised-demand-us
Pianta, R. C., \& Hamre, B. K. (2009). Conceptualization, measurement, and improvement of classroom processes: Standardized observation can leverage capacity. Educational Researcher, 38, 109119.

Pillay, H., Goddard, R., \& Wilss, L. (2005). Well-Being, Burnout and Competence : Implications for Teachers. Australian Journal of Teacher Education, 30(2). http://dx.doi.org/10.14221/ ajte. $2005 \mathrm{v} 30 \mathrm{n} 2.3$

Reyes, C. \& Valencia, M. (2014). Competitive edge of migrant Filipino teachers in selected countries. https://www.researchgate.net/ publication/268138812

Richmond, V. P., Wrench, J. C., \& Gorham, J. (2001). Communication, affect, and learning in the classroom. Acton, MA: Tapestry Press.

Sheema, A. (2005). Emotional stability among college Youth. Journal of Indian Academy of Applied Psychology, 31(1-2), 100-102.

Tamban, V., \& Banasihan G. (2017). Big Five Personality Traits and Teaching Performance of Faculty of College of Teacher Education, Laguna State Polytechnic University. International Journal of ResearchGranthaalayah, 5(9), 99-105. http://doi. org/10.5281/zenodo.999273

Tanjutco, C. (2017). Filipino teachers highly
Thompson, S \& Spacapan, S, (2010). Perceptions of control in vulnerable populations. Journal of Social Issues, 47(4), 1 - 21.

Toussi, M., \& Ghanizadeh, A. (2012). A study of EFL teachers' locus of control and self-regulation and the moderating role of self-efficacy. Theory and Practice in Language Studies, 2(11), 2363-2371.

Tsytsarev S.V., Shiryaev E.B. (2017) Addictive nature of control: An issue of the psychopathology of power. International conference "Psychology of Power." St. Petersburg, 45-49.

Viernes, R. \& de Guzman A. (2005). FilipinoTeachers' experiences of supportive relationships with colleagues: A narrative-biographical inquiry. Asia Pacific Education Review, 6(2), 137-142.

World Health Organization (2019). Burn-out an "occupational phenomenon": International Classification of Diseases.

Yazon, A. \& Manaig, K. (2019). Emotional Intelligence, and Occupational Stress among Filipino Teachers. Universal Journal of Educational Research, 7(11): 2303-2313. 